\title{
Emerging Infections Program Efforts to Address Health Equity
}

\author{
James L. Hadler, Duc J. Vugia, Nancy M. Bennett, Matthew R. Moore
}

The Emerging Infections Program (EIP), a collaboration between (currently) 10 state health departments, their academic center partners, and the Centers for Disease Control and Prevention, was established in 1995. The EIP performs active, population-based surveillance for important infectious diseases, addresses new problems as they arise, emphasizes projects that lead to prevention, and develops and evaluates public health practices. The EIP has increasingly addressed the health equity challenges posed by Healthy People 2020. These challenges include objectives to increase the proportion of Healthy People-specified conditions for which national data are available by race/ethnicity and socioeconomic status as a step toward first recognizing and subsequently eliminating health inequities. EIP has made substantial progress in moving from an initial focus on monitoring social determinants exclusively through collecting and analyzing data by race/ethnicity to identifying and piloting ways to conduct population-based surveillance by using area-based socioeconomic status measures.

$\mathrm{D}$ escribing health disparities and achieving health equity have been priorities of the national public health agenda for the past 20 years. One of the 2 goals of Healthy People (HP) 2010, the public health agenda for 2000-2010, was to "eliminate health disparities among different segments of the population, including differences that occur by gender, race or ethnicity, education or income, disability, geographic location, or sexual orientation" (1). In addition, HP 2010 included a related public health infrastructure objective (23.4), to track HP 2010 objectives by each population group. HP 2020, the agenda for 2010 2020, specifically added mention of social determinants of health. It reframed the goal and the related infrastructure objective, the former as "Achieve health equity, eliminate disparities, and improve the health of all groups," and the latter, now Public Health Infrastructure Objective (7.1), as

Author affiliations: Connecticut Emerging Infections Program, Yale School of Public Health, New Haven, Connecticut, USA (J.L. Hadler); California Emerging Infections Program, California Department of Public Health, Richmond, California, USA (D.J. Vugia); New York Emerging Infections Program, University of Rochester Medical Center, Rochester, New York, USA (N.M. Bennett); Centers for Disease Control and Prevention, Atlanta, Georgia, USA (M.R. Moore)

DOI: http://dx.doi.org/10.3201/eid2109.150275
"Increase the proportion of population-based Healthy People 2020 objectives for which national data are available for all population groups" with a specific subobjective (7.3) "by socioeconomic status" (2).The World Health Organization, in a similar vein, recently recognized that addressing the social determinants of health was a key priority to eventually achieving health equity (3).

The Emerging Infections Program (EIP), established by the Centers for Disease Control and Prevention (CDC) in 1995, is a network that now includes 10 state health departments and their collaborators in local health departments, academic institutions, other federal agencies, and public health and clinical laboratories, with a catchment area of $\approx 44$ million persons (4-7). In addition to performing active, population-based surveillance for important infectious diseases, EIP activities are intended to be flexible and address new problems as they arise, answer critical public health questions, emphasize projects that lead to prevention, and develop and evaluate public health practices. In this context, the EIP has increasingly taken on the challenges posed by HP 2010 and HP 2020, moving from a focus on monitoring social determinants exclusively through collecting and analyzing data by race/ethnicity to identifying and piloting ways to conduct population-based surveillance by using socioeconomic status (SES) measures with an ultimate focus on working toward health equity.

Most data collected by EIP sites comes from laboratory-based surveillance for bacterial, parasitic, and viral diseases, which does not include individual-level SES information. Missing data, especially ethnicity, is a consistent challenge. However, because residency in an EIP catchment area is a requirement for inclusion in surveillance, and to enable deduplication of multiple reports, addresses of residence for individual case-patients are collected at the time of diagnosis, making it possible to link cases to specific census tracts. With linkage to census tract, a wealth of data on census tract-level SES status indicators (e.g., poverty, education level, crowding) becomes available. Seminal work done by Nancy Krieger and colleagues in the Public Health Disparities Geocoding Project found that these census tract-level SES measures, especially low SES status (usually the lowest quartile or quintile of each measure), often predict disease incidence and mortality rates $(8,9)$ and do so within and across groups defined by race/ethnicity. These authors recommended routine use of area-based SES 


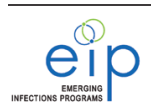

measures in disease surveillance to describe and monitor, over time, disparities by SES, particularly poverty as measured by the percentage of persons in a census tract who lived below the federal poverty level.

In this article, we describe the evolution of EIP involvement in monitoring health disparities and in working toward health equity. These efforts began with a focus on race/ethnicity and, more recently, have included the piloting use of area-based SES measures under the guidance of a Health Equity Working Group.

\section{EIP and Health Disparities}

To date, EIP population-based surveillance data (from single or multiple sites) have been used to describe racial and socioeconomic disparities for invasive pneumococcal disease (IPD), invasive group B Streptococcus (GBS) disease, invasive group A Streptococcus (GAS) disease, influenza-associated hospitalizations, and several other diseases (10-32).

\section{IPD (Streptococcus pneumoniae)}

Racial disparities in the incidence of IPD have long been described (10). Before the 7-valent pneumococcal conjugate vaccine (PCV7) was introduced in the United States in 2000, IPD rates among blacks had been documented by the EIP to be approximately twice that of whites, and this disparity was seen in all age groups (11). After PCV7 was introduced, the racial disparity in IPD, caused by bacterial serotypes included in PCV7, was eliminated for children $<5$ years of age, and rates among white children decreased below the HP 2010 target of 46 cases per 100,000 population by 2001 (12-14). Rates for black children met this goal a year later. However, incidence rates for those $\geq 5$ years of age remained higher among blacks.

The most recent analysis of national EIP IPD data tracked the effects of trends in PCV7-type and nonPCV7-type IPD rates on racial disparities (15). Although incidence of IPD caused by PCV7-types was nearly eliminated in blacks and whites after PCV7 was introduced, rates of non-PCV7-type IPD increased in both races so that, by 2009, non-PCV7-type IPD incidence among blacks was still much higher than that among whites, in all age groups (15). Research has suggested that these findings may be due to a higher prevalence of underlying conditions among blacks (e.g., asthma, diabetes, HIV/AIDS) and lower SES (16-18).

The first analysis of IPD data that controlled for SES by using census tract measures was a study of 1994-1997 rates in San Francisco County, published by the California EIP (19). In a Poisson model, black race and living in census tracts with low median household income were both highly significantly associated with higher IPD rates. In an analysis of 2003-2004 bacteremic pneumonia (caused by
S. pneumoniae, Haemophilus influenzae, GAS, and GBS), data from 9 EIP sites showed that the rates were highest among US adults living in the poorest census tracts (with $\geq 20 \%$ of persons living below federal poverty level) and among blacks (20). In models that controlled for age, census tract poverty level, and EIP site, "racial disparities in incidence were reduced but remained significant." This article was notable for using geocoded EIP surveillance data and linking such data to the 2000 US census tract data for the analyses, following the method of the Public Health Disparities Geocoding Project (8).

The Connecticut EIP also used this method to analyze and describe the changing disparities in IPD incidence rates in Connecticut during 1998-2008 by SES and by race/ethnicity (21). The authors found that before the introduction of PCV7, persons living in high-poverty census tracts had a much higher incidence of IPD than their counterparts in low-poverty census tracts. After PCV7 was introduced, these differences nearly disappeared for those infected with PCV7 serotypes but increased for those infected with nonPCV7 serotypes.

\section{Invasive GBS Disease}

Racial disparities have also been described for invasive GBS disease. In the late 1980s, black infants in metropolitan Atlanta were found to have a higher risk for early- and late-onset GBS disease than white infants (22), and black adults had higher rates of invasive GBS infections than white adults (23).

Coincident with active efforts in the mid-1990s to provide antimicrobial prophylaxis to pregnant women at risk of transmitting GBS to their newborns, EIP data documented that early-onset invasive GBS disease had decreased substantially by 1998 for both white and black neonates, but the incidence in black neonates remained higher than that in whites (24). The 2010 national health objective of 0.5 cases per 1,000 live births has been reached among white neonates since 1998; although the incidence for black neonates has been approaching this goal, it had not been achieved by 2003 (25). Indeed, through 2006, EIP surveillance data showed that the rate of early-onset invasive GBS disease had increased for black infants, particularly preterm black infants, widening the gap between black and white infants $(26,27)$. During 1990-2005, the incidence of late-onset neonatal GBS disease, which intrapartum antibiotic prophylaxis does not prevent, was also higher among black infants than among white infants (28).

In addition to disparities for GBS disease, disparities are found for other causes of neonatal sepsis. During 2005-2008, EIP surveillance documented that rates of early-onset neonatal sepsis (caused by GBS, Escherichia coli, viridans streptococci, and other bacteria) among black preterm infants were $>10$ times those of nonblack term infants 
(5.14 vs. 0.4 cases/1,000 live births) (29). The authors of this study commented that race is likely a surrogate for social determinants of health that contribute more broadly to disease disparities.

\section{Invasive GAS Disease}

The epidemiology of invasive GAS disease in the United States was described by using 1995-1999 population-based surveillance data from several EIP sites (30). The incidence of invasive GAS disease among blacks was 1.6 times higher than incidence among other racial groups. The higher incidence of invasive GAS disease among blacks was confirmed in another analysis of 1989-1999 surveillance data from the California EIP (31). The authors suggested that race may be a surrogate marker for other, unmeasured, factors such as access to health care.

\section{Influenza}

The Connecticut EIP analyzed influenza-associated hospitalizations and census tract SES following the process used by the Public Health Disparities Geocoding Project (8). In one analysis, 2003-2010 influenza-associated hospitalization cases among children $<18$ years of age were geocoded and linked to 2000 census tract SES data (32). The mean annual incidence of influenza-associated hospitalizations for children in high-poverty and high-crowding census tracts was at least 3 times greater than that in lowpoverty and low-crowding tracts. This disparity could not be fully explained by prevalence of underlying conditions or receipt of influenza vaccination. Incidences of influenzaassociated hospitalization among black and Latino children were 3.4 and 3.0 times higher, respectively, than among white children.

In another analysis, 2007-2011 influenza-related hospitalization cases of adults $\geq 18$ years old were geocoded and linked to 2006-2010 American Community Survey data for census tract SES measures (33). Again, a statistically significant trend was found: the incidence of influenza-related hospitalizations increased as SES decreased (or poverty increased), for each influenza season and within each racial/ethnic group. Black and Latino adults had higher influenza hospitalization rates than white adults within each SES group, and rates for women were higher than those for men for each age group. The study authors noted that systematic efforts are needed to achieve higher influenza vaccination rates in low SES neighborhoods and among women.

\section{Campylobacteriosis}

The Connecticut EIP geocoded 1999-2009 cases of campylobacteriosis and linked them to 2000 census tract data to analyze for case-patient SES (34). For children $<10$ years of age, campylobacteriosis rates increased as census tract poverty level increased, but for children $\geq 10$ years of age and for adults, rates decreased as census tract poverty level increased. The authors stated that children living in poorer census tracts could conceivably have a higher rate of exposure to Campylobacter spp. in the home, although this possibility needed to be verified.

\section{Cervical Cancer Precursors}

Again using methods of the Public Health Disparities Geocoding Project, the Connecticut EIP linked 2008-2009 Connecticut cases of cervical intraepithelial neoplasia grade 2 or higher and adenocarcinoma in situ (CIN2+/AIS), cervical cancer precursors, with poverty level as determined from 2000 census tract data (35). The authors found that, overall, higher rates of CIN2+/AIS were associated with higher levels of poverty and that the association of higher proportions of African American residents with poverty was the strongest and most consistently associated measure. Among women 20-24 years of age, however, CIN2+/ AIS rates were inversely associated with poverty, a finding suggesting that screening rates are higher among those living in SES census tracts where income level is higher.

EIP population-based surveillance data analyses have contributed to identification or confirmation of race- and SES-based health disparities for several diseases under EIP surveillance. Linking geocoded surveillance data to census tract SES measures has shed further light on the influence of neighborhood poverty on some of these diseases. Notably, when interventions have decreased infection rates of IPD and invasive GBS significantly, some racial disparities remained. Although the underlying reasons for racial disparities associated with these diseases await further investigation, identifying such disparities on the basis of SES provides opportunities for focusing prevention efforts to populations defined by SES rather than solely by race/ethnicity.

\section{EIP Health Equity Working Group}

In 2012, the EIP commissioned an external review to seek advice about future directions and strategies. Among other issues, the external review panel was asked specifically to identify areas for increased emphasis considering the extant portfolio of work, the strengths and composition of the network, and key public health issues involving infectious diseases. The panel responded: "EIP should develop and implement a plan for studying the role and [causal] pathways of underlying determinants of health in creating infectious disease disparities, and the extent to which these pathways are similar or different across diseases" (EIP External Review Report, 2012). This recommendation was discussed extensively at the 2013 meeting of the EIP Steering Committee and, as a result, the EIP Health Equity Working Group was formed. Members of the Working Group include interested collaborators from the EIP sites 


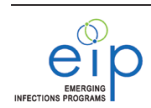

as well as CDC staff. The goals of the working group are to describe disparities and the contributions of various social determinants of health, to target and evaluate the effects of interventions aimed at reducing disparities, and, to the extent possible, to develop and test hypotheses regarding the causal pathways that lead to disparities in conditions studied by the EIP.

To focus on the social determinants of health, the working group determined that it was critical to move beyond an analysis exclusively based on race/ethnicity and to take advantage of having the residence address of case-patients. The addresses can be geocoded routinely and linked to census tract-level socioeconomic data as described (8). An approach using area-based SES data to describe health disparities provides certain advantages over EIP's previous approach based on race/ethnicity (12). Although race/ethnicity and SES are associated in the United States, use of race/ethnicity as a proxy for SES has distinct limitations. Race and especially ethnicity are often missing from inpatient medical records, requiring the use of complex methods to impute unknown values (8). In addition, unlike income or educational level, race/ethnicity is not modifiable, and it has been biologically causally linked to disparities only for certain conditions (e.g., sickle cell disease) (36). Further, SES is a determinant of health within groups defined by race/ethnicity, something not measured when race/ ethnic group is the variable of analysis (8). Finally, using race/ethnicity as a proxy for SES in the absence of other measures fails to capture the full spectrum of social determinants of disease and makes it difficult to accurately target interventions.

One of the strengths of the EIP is that methods are standardized among the 10 geographically distributed sites. The first order of business for the Health Equity Working Group

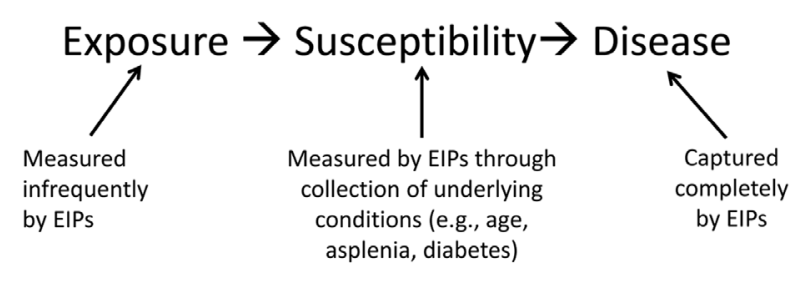

Figure 1. Simplified causal pathway previously accessible by using Emerging Infections Program (EIP) data.

was to develop a standardized protocol for geocoding cases to the census tract level. Case-patients that are college students or residents of long-term care facilities, for example, often have at least 2 addresses to which they could be geocoded, and this protocol ensures they are geocoded in the same way by all EIP sites. A variety of geocoding software is now available, and it varies in its ability to geocode cases to the rooftop level, a method which is necessary to accurately assign addresses to census tracts (37). Although individual EIP sites are not required to use the same software, the protocol does require the use of software capable of geocoding to the rooftop level. Privacy concerns have been addressed by limiting retention of address information to the local EIP sites. For activities that might involve small numbers of potentially identifiable case-patients, additional methods are available to protect confidentiality (38). In addition, the EIP affords investigators an opportunity to use the best possible analytic approaches to better define the influence of a variety of social determinants.

\section{Future Directions}

Although the EIP has substantial experience in evaluating the effects of public health interventions, including some that have reduced racial disparities, the EIP has less

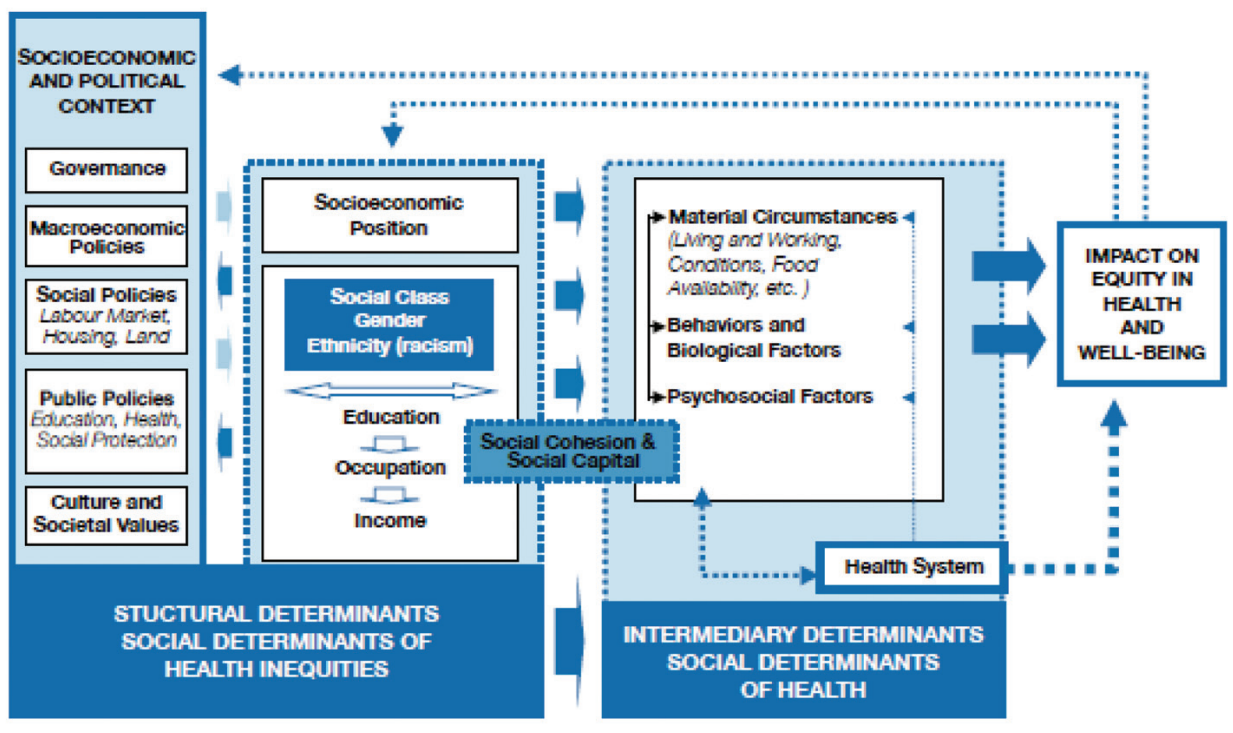

Figure 2. Framework for considering social disparities of health determined by the Commission on Social Determinants of Health, World Health Organization (3). 
experience developing and testing hypotheses regarding the causal pathways that lead to health disparities in the first place. Instead, the EIP has historically collected basic demographic data (age, sex, race/ethnicity) and clinical data available from the inpatient medical record (date of hospitalization and presence of underlying conditions such as diabetes and heart disease). These limited data lend themselves to only a simple causal pathway (Figure 1). The causal pathway to direct exposure to infections monitored by the EIPs, such as exposure to respiratory pathogens, is extremely difficult to determine in nonoutbreak settings. On the other hand, assessing individual-level susceptibility, such as that conferred by certain underlying conditions, is relatively straightforward to measure through review of medical records. But this simplistic model misses separate but important dimensions of risk of disease.

In contrast, the World Health Organization's Commission on Social Determinants of Health has adopted a more complex framework for considering the nature of health disparities (Figure 2) (3). Under this framework, interventions are aimed at the circumstances of daily life and the structural drivers of disparities. The former includes differential exposure to disease, such as those that occur early in life, those that affect social and physical environments, and work, all of which are associated with differences in social strata. The structural drivers of disparities include the nature and degree of social stratification; biases, norms, and values within societies; global and national economic and social policy; and processes of governance at global, national, and local levels.

The commission also made several recommendations, including one to "measure the problem, evaluate action, expand the knowledge base, develop a workforce that is trained in the social determinants of health, and raise public awareness about the social determinants of health." To respond to that recommendation, the EIP will need to broaden its scope of expertise and collaborate with new partners. These partners could include, for example, academic investigators who are advancing our understanding of the biologic basis for the effects of social position on risk of disease (39) and professional organizations that support new ways of thinking about health disparities (40). Such collaborations could shed light on ways in which the EIP could design new studies aimed at understanding the causal pathways leading to health disparities, and they could assist the EIP in becoming a vocal advocate for health equity.

\section{Acknowledgments}

We acknowledge the contributions of the members of the EIP Steering Committee and the Health Equity Workgroup for their interest in expanding EIP surveillance to include measures of socioeconomic status and to develop standardized protocols to facilitate it.
The work on this manuscript was supported directly by the Centers for Disease Control and Prevention (CDC) (M.R.M.) or by Cooperative Agreement 5U50-CK000195 from the CDC (J.L.H., D.J.V., N.M.B.). The authors have no conflicts of interest to disclose.

Dr. Hadler has worked with the EIP since its inception in 1995, first as the Connecticut State Epidemiologist and, more recently, at the Yale School of Public Health where he is clinical professor of epidemiology. He is co-chair of the Council of State and Territorial Epidemiologists Health Disparities Subcommittee. His research interests include infectious disease surveillance and prevention and health inequities.

\section{References}

1. US Department of Health and Human Services. Healthy People 2010: understanding and improving health. 2nd ed. Washington (DC): US Government Printing Office; 2000. p. 11 [cited 2015 Apr 11]. http://www.healthypeople.gov/2010/document/pdf/ uih/2010uih.pdf

2. US Department of Health and Human Services. Healthy People 2020 topics and objectives: public health infrastructure [cited 2015 Apr 11]. http://www.healthypeople.gov/2020/topics-objectives/ topic/public-health-infrastructure/objectives

3. Commission on Social Determinants of Health. Closing the gap in a generation: health equity through action on the social determinants of health. Final report of the Commission on Social Determinants of Health. Geneva: the Commission; 2008 [cited 2015 Apr 11]. http://www.who.int/social_determinants/thecommission/finalreport/en/

4. Centers for Disease Control and Prevention. Emerging Infections Programs [cited 2015 Apr 11]. http://www.cdc.gov/ncezid/dpei/eip/ index.html

5. Pinner RW. Addressing the challenges of emerging infectious disease. Am J Med Sci. 1996;311:3-8. http://dx.doi.org/ 10.1097/ 00000441-199601000-00002

6. Pinner RW, Rebmann CA, Schuchat A, Hughes JM. Disease surveillance and the academic, clinical, and public health communities. Emerg Infect Dis. 2003;9:781-7. http://dx.doi.org/ 10.3201/eid0907.030083

7. Pinner RW, Lynfield R, Hadler JL, Schaffner W, Farley MM, Frank ME, et al. Cultivation of an adaptive domestic network for surveillance and evaluation of emerging infections. Emerg Infect Dis. 2015;21;1499-1509.

8. Krieger N, Chen JT, Waterman PD, Rehkopf DH, Subramanian SV. Painting a truer picture of US socioeconomic and racial/ ethnic health inequalities: The Public Health Disparities Geocoding Project. Am J Public Health. 2005;95:312-23. http://dx.doi.org/10.2105/AJPH.2003.032482

9. Public Health Disparities Geocoding Project Monograph [cited 2015 Feb 15]. http://www.hsph.harvard.edu/thegeocodingproject

10. Bennett NM, Buffington J, LaForce FM. Pneumococcal bacteremia in Monroe County, New York: incidence, case fatality, and comorbid conditions. Am J Public Health. 1992;82:1513-16. http://dx.doi.org/10.2105/AJPH.82.11.1513

11. Robinson KA, Baughman W, Rothrock G, Barrett NL, Pass M, Lexau C, et al. Epidemiology of invasive Streptococcus pneumoniae infections in the United States, 1995-1998. Opportunities for prevention in the conjugate vaccine era. JAMA. 2001;285:1729-35. http://dx.doi.org/10.1001/jama.285.13.1729

12. Flannery B, Schrag S, Bennett NM, Lynfield R, Harrison LH, Reingold A, et al. Impact of childhood vaccination on racial disparities in invasive Streptococcus pneumoniae infections. JAMA. 2004;291:2197-203. http://dx.doi.org/10.1001/jama.291.18.2197 
13. Talbot TR, Poehling KA, Hartert TV, Arbogast PG, Halasa NB, Mitchel E, et al. Elimination of racial differences in invasive pneumococcal disease in young children after introduction of the conjugate pneumococcal vaccine. Pediatr Infect Dis J. 2004;23:72631. http://dx.doi.org/10.1097/01.inf.0000133046.60555.de

14. Poehling KA, Talbot TR, Griffin MR, Craig AS, Whitney CG, Zell E, et al. Decline in invasive pneumococcal disease among young infants and elimination of racial differences in disease rates following introduction of the pneumococcal conjugate vaccine. JAMA 2006;295:1668-74. http://dx.doi.org/10.1001/jama.295.14.1668

15. Wortham JM, Zell ER, Pondo T, Harrison LH, Schaffner W, Lynfield R, et al. Racial disparities in invasive Streptococcus pneumoniae infections, 1998-2009. Clin Infect Dis. 2014;58:12507. http://dx.doi.org/10.1093/cid/ciu108

16. US Department of Health and Human Services (DHHS). HHS action plan to reduce health disparities: a nation free of disparities in health and health care. Washington (DC): The Department; 2011 [cited 2015 Apr 12]. http://minorityhealth.hhs.gov/npa/files/Plans/ HHS/HHS_Plan_complete.pdf

17. Ramakrishnan M, Moisi JC, Klugman KP, Iglesias JM, Grant LR, Mpoudi-Etame M, et al. Increased risk of invasive bacterial infections in African people with sickle-cell disease: a systematic review and meta-analysis. Lancet Infect Dis. 2010;10:329-37. http://dx.doi.org/10.1016/S1473-3099(10)70055-4

18. Muhammad RD, Oza-Frank R, Zell E, Link-Gelles R, Narayan KM, Schaffner W, et al. Epidemiology of invasive pneumococcal disease among high-risk adults since the introduction of pneumococcal conjugate vaccine for children. Clin Infect Dis. 2013;56:e59-67. http://dx.doi.org/10.1093/cid/cis971

19. Nuorti JP, Butler JC, Gelling L, Kool JL, Reingold AL, Vugia DJ. Epidemiologic relation between HIV and invasive pneumococcal disease in San Francisco County, California. Ann Intern Med. 2000;132:182-90. http://dx.doi.org/10.7326/0003-4819-1323-200002010-00003

20. Burton DC, Flannery B, Bennett NM, Farley MM, Gershman K, Harrison LH, et al. Socioeconomic and racial/ethnic disparities in the incidence of bacteremic pneumonia among US adults. Am J Public Health. 2010;100:1904-11. http://dx.doi.org/10.2105/ AJPH.2009.181313

21. Soto K, Petit S, Hadler JL. Changing disparities in invasive pneumococcal disease by socioeconomic status and race/ethnicity in Connecticut, 1998-2008. Public Health Rep. 2011;126(Suppl 3):81-8.

22. Schuchat A, Oxtoby M, Cochi S, Sikes RK, Hightower A, Plikaytis B, et al. Population-based risk factors for neonatal group B streptococcal disease: results of a cohort study in metropolitan Atlanta. J Infect Dis. 1990;162:672-7. http://dx.doi.org/10.1093/ infdis/162.3.672

23. Schwartz B, Schuchat A, Oxtoby MJ, Cochi SL, Hightower A, Broome CV. Invasive group B streptococcal disease in adults. A population-based study in metropolitan Atlanta. JAMA. 1991;266:1112-4. http://dx.doi.org/10.1001/jama.1991. 03470080082034

24. Schrag SJ, Zywicki S, Farley MM, Reingold AL, Harrison LH, Lefkowitz LB, et al. Group B streptococcal disease in the era of intrapartum antibiotic prophylaxis. N Engl J Med. 2000;342:15-20. http://dx.doi.org/10.1056/NEJM200001063420103

25. Centers for Disease Control and Prevention. Diminishing racial disparities in early-onset neonatal group B streptococcal diseaseUnited States, 2000-2003. MMWR. Morb Mortal Wkly Rep. 2004;53:502-5.

26. Centers for Disease Control and Prevention. Perinatal group B streptococcal disease after universal screening recommendations-
United States, 2003-2005. MMWR. Morb Mortal Wkly Rep. 2007;56:701-5.

27. Centers for Disease Control and Prevention. Trends in perinatal group B streptococcal disease-United States, 2000-2006. MMWR. Morb Mortal Wkly Rep. 2009;58:109-12.

28. Jordan HT, Farley MM, Craig A, Mohle-Boetani J, Harrison LH, Petit S, et al. Revisiting the need for vaccine prevention of late-onset neonatal group B streptococcal disease: a multistate, populations-based analysis. Pediatr Infect Dis J. 2008;27:1057-64. http://dx.doi.org/10.1097/INF.0b013e318180b3b9

29. Weston EJ, Pondo T, Lewis MM, Martell-Cleary P, Morin C, Jewell B, et al. The burden of invasive early-onset neonatal sepsis in the United States, 2005-2008. Pediatr Infect Dis J. 2011; 30:937-41. http://dx.doi.org/10.1097/INF.0b013e318223bad2

30. O'Brien KL, Beall B, Barrett NL, Cieslak PR, Reingold A, Farley MM, et al. Epidemiology of invasive group A Streptococcus disease in the United States, 1995-1999. Clin Infect Dis. 2002; 35:268-76. http://dx.doi.org/10.1086/341409

31. Passaro DJ, Smith DS, Hett EC, Reingold AL, Daily P, Van Beneden CA, et al. Invasive group A streptococcal infections in the San Francisco Bay area, 1989-1999. Epidemiol Infect. 2002;129:471-8. http://dx.doi.org/10.1017/S0950268802007823

32. Yousey-Hindes KM, Hadler JL. Neighborhood socioeconomic status and influenza hospitalizations among children: New Haven County, Connecticut, 2003-2010. Am J Public Health. 2011;101:1785-9. http://dx.doi.org/10.2105/AJPH.2011.300224

33. Tam K, Yousey-Hindes K, Hadler JL. Influenza-related hospitalization of adults associated with low census tract socioeconomic status and female sex in New Haven County, Connecticut, 2007-2011. Influenza Other Respir Viruses. 2014; 8:274-81. http://dx.doi.org/10.1111/irv.12231

34. Bemis K, Marcus R, Hadler JL. Socioeconomic status and campylobacteriosis, Connecticut, USA, 1999-2009 [Letter]. Emerg Infect Dis. 2014;20:1240-2.

35. Niccolai LM, Julian PJ, Bilinski A, Mehta NR, Meek JI, Zelterman D, et al. Geographic povery and racial/ethnic disparities in cervical cancer precursor rates in Connecticut, 2008-2009. Am J Public Health. 2013;103:156-63. http://dx.doi.org/ 10.2105/AJPH.2011.300447

36. Lembo NJ. Pneumococcal infections in children with sickle cell disease: increased incidence, immunological defects, vaccine failure, and prospects for the future. J Natl Med Assoc. 1981;73:43-5.

37. Roongpiboonsopit D, Harimi HA. Quality assessment of online street and rooftop geocoding services. Cartogr Geogr Inf Sci. 2010;37:301-18. http://dx.doi.org/10.1559/152304010793454318

38. Hampton KH, Fitch MK, Allshouse WB, Doherty IA, Gesink DC, Leone PA, et al. Mapping health data: improved privacy protection with donut method geomasking. Am J Epidemiol. 2010;172:10629. http://dx.doi.org/10.1093/aje/kwq248

39. McEwen BS. Protective and damaging effects of stress mediators. N Engl J Med. 1998;338:171-9. http://dx.doi.org/10.1056/ NEJM199801153380307

40. Shonkoff JP, Garner AS, Committee on Psychosocial Aspects of Child and Family Health; Committee on Early Childhood, Adoption, and Dependent Care; Section on Developmental and Behavioral Pediatrics. The lifelong effects of early childhood adversity and toxic stress. Pediatrics 2012;129:e232-46. http://dx.doi.org/10.1542/peds.2011-2663

Address for correspondence: James L. Hadler, Emerging Infections Program, Yale School of Public Health, One Church St, 7th Fl,

New Haven, CT 06511, USA; email: hadler-epi@att.net 